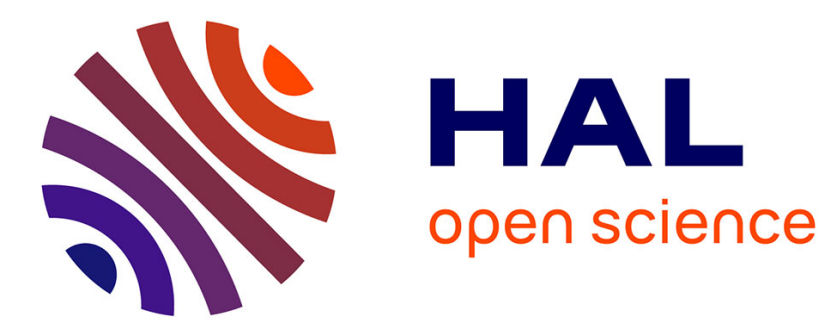

\title{
The Structure and Management of Conflict: Fighting or Defending the Status Quo
}

\author{
Carsten K. W. de Dreu, Esther S. Kluwer, Aukje Nauta
}

\section{To cite this version:}

Carsten K. W. de Dreu, Esther S. Kluwer, Aukje Nauta. The Structure and Management of Conflict: Fighting or Defending the Status Quo. Group Processes and Intergroup Relations, 2008, 11 (3), pp.331-353. 10.1177/1368430208090646 . hal-00571691

\section{HAL Id: hal-00571691 \\ https://hal.science/hal-00571691}

Submitted on 1 Mar 2011

HAL is a multi-disciplinary open access archive for the deposit and dissemination of scientific research documents, whether they are published or not. The documents may come from teaching and research institutions in France or abroad, or from public or private research centers.
L'archive ouverte pluridisciplinaire HAL, est destinée au dépôt et à la diffusion de documents scientifiques de niveau recherche, publiés ou non, émanant des établissements d'enseignement et de recherche français ou étrangers, des laboratoires publics ou privés. 


\title{
The Structure and Management of Conflict: Fighting or Defending the Status Quo
}

\author{
Carsten K. W. De Dreu \\ University of Amsterdam
}

Esther S. Kluwer

Utrecht University

\author{
Aukje Nauta \\ University of Amsterdam and Randstad HR Solutions
}

\begin{abstract}
Although conflict and negotiation studies have examined symmetrical structures in which both parties want change, or asymmetrical structures in which one party wants change and the other to maintain the status quo, no research provided a direct comparison of both structures. Two experiments were conducted to fill this void. Results show that in asymmetrical structures challengers engage in more problem solving and more contending, have less of a loss frame and perceive less control than defendants, and are perceived be less successful. In symmetrical structures, behavior and attitudes of parties are more alike and there is more reciprocation of problem solving and yielding. Furthermore, findings reveal that challengers see their defendant as less friendly and more dominant than defendants see their challengers. Finally, no evidence was obtained that social value orientation moderates these effects. Implications for conflict theory and research, and for third party interventions in symmetrical versus asymmetrical conflicts, are discussed.
\end{abstract}

KEYWORDS conflict, conflict management, negotiation, power, status quo

IN HIs 1986 address to the American Psychological Association, Coombs (1987) argued that some conflicts arise because opposing individuals want the same thing and must settle for different things, as when leaders from different teams claim the same excess budget, when children desire the same toy to play with, or when neighboring states desire hegemony of the same group of islands. Other conflicts arise because individuals want different things and must settle for the same thing, as when husband and wife need to decide where to have dinner or how many children to aim for, or when labor and management decide about a downsizing strategy.

\footnotetext{
Author's note

Address correspondence to Carsten K. W. De Dreu, Department of Psychology, University of Amsterdam, Roetersstraat 15, 1081 WB Amsterdam, The Netherlands [email: c.k.w.dedreu@uva.nl]
} 
Although Coombs notes that these two broad classes of conflict structures 'exhaust the domain of conflict' (p. 362), it is important to note that in both types of conflict a further distinction can be made, namely between symmetrical and asymmetrical structures. We concur with Coombs (1987) that 'individuals, in spite of how they may assess their status quo in any absolute terms, are motivated to improve on the status quo and to avoid worsening it' (p. 358). However, we argue that many conflicts are asymmetrical in that one party (defendant) is primarily motivated to maintain the status quo whereas its counterpart (challenger) is primarily motivated to change it. Thus, the Falkland War was about Argentina contesting Britain's 'colonial' hegemony over the group of islands just off the Argentinean coast-Argentina attacked the status quo and the United Kingdom defended it. Martin Luther King's dream was about changing the status quo that was induced and defended by the White majority. Many union-led strikes are motivated by the desire to block management's desire to change the status quo in terms of job securities and fringe benefits, and some marital conflicts are not about how many children to aim for, but about one spouse desiring children and the other wishing to maintain the quiet and peaceful (in terms of children-caused noise) status quo.

Despite decades of social psychological research into conflict and dispute resolution, little systematic research has been invested in comparing symmetrical and asymmetrical structures. ${ }^{1}$ This is unfortunate because there is good reason to believe that the structure of the conflict in and by itself has important implications for the way parties manage their conflict, perceive their counterparts, and thus for the probability of the conflict escalating into intractable disputes. However, we do not exactly know the differences between symmetrical and asymmetrical conflicts. Symmetrical conflicts are primarily examined in the (laboratory) context of interpersonal negotiations (De Dreu, Beersma, Steinel \& Van Kleef, 2007; Pruitt, 1998). Asymmetrical conflicts are primarily examined in the (field) context of marital relations (Christensen \& Heavey, 1990; Heavey, Layne, \& Christensen, 1993; Klinetob \&
Smith, 1996; Kluwer, 1998; Kluwer, Heesink, \& Van de Vliert, 1996, 1997, 2000), and judicial disputes and liability negotiations (Fobian \& Christensen-Szalanski, 1993, 1994; Garcia, Darley, \& Robinson, 2001; Peirce, Pruitt, \& Czaja, 1993). Furthermore, work on asymmetrical conflict is constrained by the fact that a party's position (challenger vs. defender) covaries with other relevant variables, including one party's gender (female vs. male, respectively) or occupational status (district attorney vs. public defender, respectively). It thus is difficult to tell whether, first of all, systematic differences between symmetrical and asymmetrical conflict exist and, second, whether such differences should be attributed to the party's specific position in the dispute, some covarying variable, or both.

The present study was designed to redress this situation, and we present a series of experimental studies in which we tested predictions about the effect of conflict structures on conflict-related cognition, interpersonal perception, and conflict management. Predictions were derived from work on gain-loss framing and the endowment effect (Kahneman, Knetsch \& Thaler, 1990; Kahneman \& Tversky, 1984), work on the status quo bias (Ritov \& Baron, 1992; Samuelson \& Zeckhauser, 1988; Schweitzer, 1994), and studies on power relations and interpersonal perception (Fiske, 1993).

\section{Cognitive, motivational, and behavioral consequences of different conflict structures}

In symmetrical conflicts each side desires a change in the status quo and needs the other side to consent or even work along. Most negotiations have such a symmetrical structure-both negotiators want something their counterparts has, and both negotiators only want to give up what they have in exchange for some alternative not in their possession. Thus, negotiators exchange their used car for money, an increase in salary in return for higher production targets, arms reduction in return for market accessibility, extra work effort in return for better career prospects, and so on. In short, both parties 
give up something in return for something else deemed more desirable, or less undesirable.

In asymmetrical conflicts one side desires a change in the status quo and needs the other side to go along, but this other side desires to maintain the status quo. Many judicial disputes and liability negotiations have this asymmetrical structure, with the district attorney seeking to change the not-guilty status quo into a 'guilty' verdict, and the plaintiff seeking to maintain the 'not-guilty' status quo. In the workplace, asymmetrical conflicts emerge when management wants change resisted by the workforce, or when customer complaints require service personnel to change their work practices and routines. Thus, whereas in symmetrical conflicts both parties seek change, in asymmetrical conflicts one seeks change and the counterparts does not. This symmetrical versus asymmetrical structure of the conflict has several important implications that reside at the cognitive, the motivational, and the strategic level.

\section{Cognitive and motivational consequences of conflict structures}

Work on human decision making has argued that those who face a choice between adopting a new strategy versus maintaining the status quo, as defendants in asymmetrical conflicts do, have a strong tendency to prefer the status quo to alternative options. This is commonly referred to as the Status Quo Bias (Samuelson \& Zeckhauser, 1988).

Schweitzer (1994) provides several reasons for the Status Quo Bias, including the notion that giving up the status quo may be felt as a loss, whereas improving upon the status quo, as challengers try to do, feels more like establishing a gain. Because losses are more averse than gains of identical size are attractive (loss aversion; Kahneman \& Tversky, 1984), people have more difficulty giving up the status quo (incurring a loss) than giving up the goal of changing it (not acquiring a gain) (cf. Bottom \& Studt, 1993; De Dreu, Carnevale, Emans, \& Van de Vliert, 1994; Neale \& Bazerman, 1985). Another reason for the Status Quo Bias is that people desire to have and maintain control over their situation.
In asymmetrical conflicts defendants control the outcome of the conflict more than challengers do (Keltner \& Robinson, 1997; Robinson \& Keltner, 1996). By giving up the status quo defendants give up a highly valued asset, namely control (also see Garcia et al., 2001).

All in all, these tendencies suggest that in asymmetrical conflicts defendants more than challengers will perceive more control, are more likely to adopt a loss-frame, and will be relatively stubborn and difficult to be persuaded to take action. In other words, it seems quite reasonable to propose that defendants have a greater sense of power than challengers, and as such may be more likely to endorse and employ power tactics to get their way. In the next section we explore such possible consequences for the ways parties in symmetrical versus asymmetrical conflict manage their dispute.

\section{Strategic considerations, conflict management, and interaction sequences}

Although exceptions can be readily identified, most individuals involved in social conflict are strongly concerned with their own outcomes. Indeed, high concern for own outcomes seems the default in interpersonal negotiation (De Dreu, Weingart, \& Kwon, 2000), and concern for own outcomes tends to have little variance across conflict participants-it is high and stable across people (Janssen \& Van de Vliert, 1996). A reasonable assumption thus is that participants in both symmetrical and asymmetrical conflicts desire to reach good outcomes, at least for themselves.

To safeguard or promote self-interest, conflict parties resort to a number of tactics and strategies. Although an infinite number of conflict tactics and strategies may be conceived of, conflict research and theory tends to converge on a four-way taxonomy that distinguishes between problem solving, contending, avoiding, and yielding (Carnevale \& Pruitt, 1992; De Dreu, Evers, Beersma, Kluwer \& Nauta, 2001; Rahim, 1983; Thomas, 1992; Van de Vliert \& Kabanoff, 1990). Problem solving tactics are oriented toward an agreement that satisfies both own and other's aspirations as much as possible, and involve an 
exchange of information about priorities and preferences, showing insights, and making tradeoffs between important and unimportant issues. Contending tactics are focused on imposing one's will on the other side, and they involve threats and bluffs, persuasive arguments, and positional commitments. Yielding tactics are oriented toward accepting and incorporating other's will, and involve unilateral concessions, unconditional promises, and offering help. Avoidance tactics involve reducing the importance of the issues, and attempts to suppress thinking about the issues.

Dispute resolution involves an exchange of tactics, and the sequence of exchange typically takes one of two forms (Olekalns \& Smith, 2000). Interaction sequences can, first of all, be reciprocal, in which case negotiators match each other's strategies exactly or in kind. Thus, problem solving tactics are reciprocated with problem solving or yielding tactics (reciprocal cooperation), and contending tactics are reciprocated with contending tactics (reciprocal competition). Second, interaction sequences can be transformational, in which negotiators mismatch strategies by pairing a cooperative and a competitive strategy. For example, problem solving tactics are reciprocated with contending tactics, and contending tactics are reciprocated with avoiding and withdrawal tactics.

Work on symmetrical conflicts, like interpersonal negotiation, generally finds reciprocal tendencies-problem-solving tactics are reciprocated, as are contending tactics (Weingart, Bazerman, Thompson, \& Carroll, 1990). Recent work further indicates that in symmetrical disputes participants start out with contending tactics, trying to persuade their counterparts to give in, and switching to problem solving tactics when continued use of contending appears to lead to costly impasse rather than one-sided victory (Brett, Shapird, \& Lytle, 1998; Harinck \& De Dreu, 2004; Harinck, De Dreu, \& Van Vianen, 2000; Olekalns \& Smith, 2005). In other words, in symmetrical conflicts where power is balanced among parties we expect relatively high levels of contending and problem solving among both parties, and no differences between parties in the amount of contending and problem solving.

Work on asymmetrical conflicts, in which defendants may perceive themselves to be relatively more powerful, generally finds transformational tendencies-problem solving and yielding tactics are paired to contending tactics, or to avoiding and withdrawal responses (and vice versa). For example, both survey and observation studies of marital interaction where husband and wife discuss the wife's desire to change and the husband's desire to maintain the status quo reveal a so-called demand-withdrawal pattern in which the wife demands change (through problem solving or through contending tactics) and the husband withdraws from the interaction (e.g. Christensen \& Heavey, 1990; Heavey et al., 1993; Kluwer, 1998). In other words, in asymmetrical conflicts we expect among challengers higher levels of contending and problem solving tactics than among defendants, who in turn display relatively high levels of avoiding tactics. This is quite consistent with work on the Status Quo Bias reviewed earlier-defendants were expected to experience more control, to be more likely to adopt a loss-frame, and to be relatively stubborn. These conflict-related cognitions undermine their tendency to reciprocate in kind their challengers' attempts at problem solving or at contending. ${ }^{2}$

\section{Hypotheses and overview of the present experiments}

Past work either focused on symmetrical or on asymmetrical conflict structures, and we are unaware of studies that directly compared the two structures in one single study design. Our goal was to fill this void, and to test several predictions about conflict management strategies and outcomes. Based on the above analysis and on results from past studies, we tested the following hypotheses:

Hypothesis 1: Challengers in asymmetrical conflicts employ more problem-solving tactics than their defendants; in symmetrical conflicts no differences in problem solving between challengers are expected. 
Hypothesis 2: Challengers in asymmetrical conflicts employ more contending tactics than their defendants; in symmetrical conflicts no differences in contending between challengers are expected.

Hypothesis 3: Challengers in asymmetrical conflicts employ fewer avoiding tactics than their defendants; in symmetrical conflicts no differences in avoiding between challengers are expected.

Hypothesis 4: Challengers in asymmetrical conflicts will feel less successful than their defendants; in symmetrical conflicts no differences in felt success between challengers are expected.

We tested these four hypotheses in two experimental studies in which participants engaged in free face-to-face interaction to solve a dispute. In both experiments we manipulated conflict structure through role instructions. In Experiment 1 we audiotaped the interaction process and coded conflict behavior. In Experiment 2 we relied on retrospective self-ratings of conflict behavior using a validated instrument. In addition, Experiment 2 assessed motivation and cognition through questionnaire measures, and addressed the moderating influence of individual differences in the inclination to cooperate or compete with one's counterpart. These issues will be introduced in more detail after Experiment 1 has been reported.

Before moving on, it is important to note that in contrast to many studies on conflict and negotiation we did not use a conflict task that led to scorable outcomes. This was done for two reasons. First, point-value tasks used in most bargaining and negotiation research often allows participants to closely monitor who is getting what, and we felt this interferes with proper testing of some of our predictions regarding conflict cognition (e.g. about loss-frame; see Experiment 2). Second, while 'objective' outcomes are certainly relevant, long-term effects of conflict relate more to perceived success and failure, and the 'softer' psychological outcomes such as hurt relationships and feelings of anger and spite (De Dreu et al., 2007). Thus, we decided to test our hypotheses regarding outcomes in terms of perceived success, rather than objective, economic outcomes.

\section{Experiment 1}

\section{Method}

Design To test the hypotheses, the experiment employed a role-playing methodology that was developed in a pilot experiment and was based on our past research (e.g. De Dreu, Nauta, \& Van de Vliert, 1995, Experiment 3). Participants were provided with background information in which a conflict situation was described, and then freely interacted with each other to discuss the issue. This interaction was audio taped and rated afterwards by four judges.

The conflict situation yielded a challenger who wanted to change the status quo coupled with either another challenger (symmetrical conflict condition) or a defendant who wanted to maintain the status quo (asymmetrical conflict condition). The design was $2 \times 2$ factorial involving Conflict Structure (Symmetrical vs. Asymmetrical) and Role (Party A, challenger vs. Party B, challenger/defendant) with Conflict Structure manipulated between dyads and Role manipulated within dyads. Dependent variables were conflict behavior and outcomes.

Participants and procedure Seventy-eight psychology students (30 males and 46 females: 2 did not indicate their gender) at the University of Groningen participated in return for the equivalent of US $\$ 5$. They were randomly assigned to dyads. The mean age of the participants was 22 years, ranging from 19 to 26 years. Initial analyses revealed no differences between male and female participants, nor between dyads composed of same or different gender.

Participants came to the laboratory in groups of four and care was taken that participants in one session were unacquainted. Participants were seated and given 10 minutes to read their role instructions (see below). Hereafter, participants were paired and seated in separate rooms where they engaged in an audiotaped conflict resolution process (see below). After 15 minutes, the experimenter entered the room and handed out a short questionnaire used to assess conflict outcomes. Hereafter, participants were debriefed and dismissed. 
Conflict task The instructions described a situation in which the participant cooperates with a fellow student on a research project. ${ }^{3}$ The original schedule of activities for the next week was that the students do statistical analyses together. In both the symmetrical and the asymmetrical condition, Party A (challenger) is told that $\mathrm{s}$ /he will start a full-time job and therefore wants to change the schedule so that the other student does the statistical analyses alone. Party A further received some background information supporting the idea that changing the original schedule was justified and that, all in all, s/ he has reason to be quite dissatisfied with the way things were going. In the symmetrical condition, participants in the role of Party B (challenger) read similar instructions: Party B wanted to change the schedule so that the other student does the statistical analyses alone, because (s) he will have an oral exam at the end of the week. Arguments were given why Party B felt that changing the original schedule was justified and that $\mathrm{s} / \mathrm{he}$ has reason to be quite dissatisfied with the way things were going. In the asymmetrical condition, Party B (defendant) wanted to maintain the original schedule for that week-s/he wanted to do the statistical analyses together with Party A. Arguments were given why $\mathrm{s} /$ he wanted to maintain the original schedule and that $\mathrm{s} /$ he felt quite satisfied with the with the way things were going.

After reading the instructions, participants were told that they had 15 minutes to discuss their preferences and to reach agreement on their schedule of activities.

\section{Dependent variables}

Conflict management The negotiations were audiotaped and coded by four trained observers unaware of the goals of the experiment. During training, observers were provided with definitions of conflict management strategies along with prototypical examples of behaviors within a particular strategy. They also coded, in practice sessions, randomly selected time intervals and discussed their observations and ratings to establish a consensual perspective. Hereafter, observers independently rated the conflict behaviors of each of the two parties within a dyad. Using electronic beeps, the 39 audiotaped conversations were divided into time samples of two minutes $(N=212$ time samples, $M=5.4$ time samples per dyad). For every two-minute interval, two observers rated the extent to which four conflict tactics (problem solving, contending, yielding, and avoiding; $1=$ demonstrated not at all, to $4=$ demonstrated to a great extent) were present for Party A and the other two observers did so for Party B. Interobserver agreement was sufficient to good, with Cohen's Kappas per time-interval varying between .67 and .98 (average Kappas for Party A and Party B were .75 and .81 , respectively). An alternative assessment using correlational analysis likewise indicated sufficient to good inter-rater agreement $(.56<r<.85)$. To account for mean differences between observer dyads original ratings of all four conflict behaviors were transformed to $\mathrm{z}$ scores, using the means and standard deviations computed per observer dyad, across all 212 time samples. ${ }^{4}$

Perceived success Participants were given a brief questionnaire to fill out immediately following the conflict resolution process, to indicate (1) whether they got what they wanted $(1=$ not at all, to $7=$ completely), and (2) whether the social relationship with their interaction partner was disturbed $(1=$ not at all, to $7=$ very much $)$. The ratings on these two items were correlated for both Party A $(r=.69)$ and Party B $(r=.58)$. Accordingly, ratings were aggregated into a perceived success to Party A and a perceived success to Party B index. Scores were recoded so that higher scores indicate more perceived success.

\section{Results}

Descriptive statistics Table 1 summarizes the means and standard deviations for all dependent variables, and gives zero-order correlations. Because asymmetrical conflict structures were supposed to evoke less reciprocal cooperation sequences, and more transformational sequences, we present zero-order correlations separately for the asymmetrical (above the diagonal in Table 1) and symmetrical conflict condition (below the diagonal in Table 1). 
Table 1. Zero-order correlations for asymmetrical conflicts (above the diagonal) and symmetrical conflicts (below the diagonal): Experiment $1(N=39)$

\begin{tabular}{lcccccccccc}
\hline & 1. & 2. & 3. & 4. & 5. & 6. & 7. & 8. & 9. & 10. \\
\hline 1. Outcome $_{\mathrm{A}}$ & - & $.49^{* *}$ & -.07 & -.22 & .34 & .10 & -.04 & -.17 & -.24 & -.09 \\
2. Outcome $_{\mathrm{B}}$ & $.73^{* *}$ & - & -.06 & $-.40^{*}$ & $.37 \&$ & $.58^{* *}$ & -.27 & -.32 & .26 & $-.44^{*}$ \\
3. Problem solving $_{\mathrm{A}}$ & -.36 & -.32 & - & .14 & $-.37 \&$ & -.03 & .11 & -.04 & $.39^{*}$ & .03 \\
4. Problem solving $_{\mathrm{B}}$ & $-.51^{* *}$ & $-.62^{* *}$ & $.47^{* *}$ & - & $-.39^{*}$ & $-.58^{* *}$ & -.15 & .02 & -.23 & $.85^{* *}$ \\
5. Contending $_{\mathrm{A}}$ & $.63^{* *}$ & $.58^{* *}$ & $-.44^{*}$ & $-.48^{* *}$ & - & $.59^{* *}$ & .14 & .30 & .23 & -.16 \\
6. Contending $_{\mathrm{B}}$ & $.56^{* *}$ & $.70^{* *}$ & -.26 & $-.58^{* *}$ & .28 & - & .12 & .26 & $.39^{*}$ & $-.49^{* *}$ \\
7. Avoiding $_{\mathrm{A}}$ & -.32 & $-.40 \&$ & .01 & $.54^{* *}$ & $-.48^{*}$ & -.32 & - & $.45^{* *}$ & -.10 & .15 \\
8. Avoiding $_{\mathrm{B}}$ & .19 & $.41 \&$ & .19 & .18 & .19 & $.39 \&$ & .13 & - & -.05 & .28 \\
9. Yielding $_{\mathrm{A}}$ & $-.48^{*}$ & $-.44^{*}$ & $.50^{* *}$ & $.60^{* *}$ & -.23 & -.19 & -.03 & .15 & - & $-.44^{*}$ \\
10. Yielding $_{\mathrm{B}}$ & -.35 & -.18 & $.73^{* *}$ & $.48^{*}$ & -.15 & -.12 & -.17 & .25 & $.64^{* *}$ & - \\
\hline
\end{tabular}

$\& p<.10 ; * p<.05 ; * * p<.025$.

Note: Subscript A = Party A; B = Party B.

A number of interesting insights derive from Table 1. First, in the asymmetrical conflict condition, perceived success to Party A (challenger) did not correlate with anything but perceived success to Party B (defendant). Party B's perceived success, in contrast, is better the less Party B engaged in problem solving $(r=-.40)$ and yielding $(r=-.44)$, and the more he or she engaged in contending $(r=.58)$. This suggests that in asymmetrical conflicts defendants determine, through problem solving and contending behavior, not only their own but also their counterpart's perceived success. In symmetrical conflicts a different pattern emerged. Here, both Party A and Party B's perceived success was positively correlated with Party A and Party B's contending behavior $(.55<r<.71)$, negatively correlated with Party A and Party B's problem solving $(-.30<r<-.62)$, and negatively correlated with Party A and Party B's yielding $(-.17<r<-.49)$. This suggests that in symmetrical conflicts challengers determine together through problem solving, contending, and yielding both their own and their counterpart's perceived success. These results are consistent with the idea that defendants exert greater control and influence over the negotiation process, and determine the perceived success to a larger extent than challengers do. That problem solving and yielding were negatively correlated, and contending was positively correlated with personal outcomes, may reflect the rather distributive nature of the task and the fact that we assessed personal (not joint) outcome.

Another interesting observation from Table 1 is that in symmetrical conflicts the correlations between both parties' problem solving $(r=.47)$, between both parties' yielding $(r=.64)$, and between one party's problem solving and the counterpart's yielding ( $r=.60$, and $r=.73)$ tendencies were all high, positive, and significant. This may reflect reciprocal cooperation. A comparison with the same correlations in the asymmetrical conflict condition shows lower and nonsignificant correlations (i.e. $r=.14, r=-.44$, $r=.03$, and $r=-.23$, respectively), which may reflect a lack of reciprocal cooperation.

\section{Conflict management (Hypotheses 1-3)}

Problem solving Hypothesis 1 predicted that challengers in asymmetrical conflicts employ more problem-solving tactics than their defendants; in symmetrical conflicts no differences in problem solving between challengers are expected. To test this hypothesis, we created two indices for problem solving (separate for Party A and Party B), and submitted these to a 2 (Symmetrical vs. Asymmetrical Conflict) $\times 2$ (Role: Party A vs. Party B) mixed-model ANOVA with the last factor within-dyads. ${ }^{5}$ Results revealed no overall effects for conflict condition $(F(1,37)=1.41, n s)$, but a significant conflict condition $\times$ party interaction $(F(1,37)=4.67, p<.05)$. As can be 
seen in Table 2, and consistent with Hypothesis 1, Party A challengers in asymmetrical conflicts engaged in more problem solving when their counterpart was in the defendant role; in the symmetrical conflict condition no differences among challengers were observed.

Contending Hypothesis 2 predicted that challengers in asymmetrical conflicts employ more contending tactics than their defendants; in symmetrical conflicts no differences in contending between challengers were expected. To test this hypothesis, we created two indices for contending (separate for Party A and Party B), and submitted these to a 2 (Symmetrical vs. Asymmetrical Conflict) $\times 2$ (Role: Party A vs. Party B) mixed-model ANOVA with the last factor within-dyads. Results revealed no overall effects for conflict condition $(F(1,37)=2.29$, $p<.14)$, but a significant conflict condition $\times$ party interaction $(F(1,37)=4.98, p<.032)$. As can be seen in Table 2, and consistent with Hypothesis 2, Party A challengers in asymmetrical conflicts engaged in more contending than their counterparts in the defendant role; in the symmetrical conflict condition no differences in contending between challengers were observed.

Avoiding Hypothesis 3 predicted that challengers in asymmetrical conflicts employ fewer avoiding tactics than their defendants; in symmetrical conflicts no differences in avoiding between challengers were expected. To test this hypothesis, we created two indices for avoiding (separate for Party A and Party B), and submitted these to a 2 (Symmetrical vs. Asymmetrical Conflict) $\times 2$ (Role: Party A vs. Party B) mixed-model ANOVA with the last factor within-dyads. There were no significant effects involving conflict condition ( all $F(1,37)$ $<2.21$, all $p>.14$ ). However, and consistent with Hypothesis 3, in asymmetrical conflicts Party A challengers engaged in less avoiding than Party B defendants $(M=-0.62$ vs. $M=0.59$; $t(18)=2.03, p<.10)$.

Yielding We had no specific hypothesis regarding yielding. For exploratory purposes, we created two indices for yielding (separate for Party A and Party B), and submitted these to a 2 (Symmetrical vs. Asymmetrical Conflict) $\times 2$ (Role: Party A vs. Party B) mixed-model ANOVA with the last factor within-dyads. No effects involving conflict condition were found (all $F \mathrm{~s}<2.00, p \mathrm{~s}>.21$ ).

Perceived success (Hypothesis 4) To test Hypothesis 4, we submitted the perceived success of Party A and the perceived success of Party B to a 2 (Symmetrical vs. Asymmetrical Conflict) $\times 2$ (Role: Party A vs. Party B) mixed-model ANOVA with the last factor within-dyads. Results revealed no main effect for conflict condition $(F(1,37)=1.85, n s)$, but a significant conflict

Table 2. Means for perceived success and conflict management as a function of conflict structure and party role

\begin{tabular}{|c|c|c|c|c|}
\hline & \multicolumn{4}{|c|}{ Conflict structure } \\
\hline & \multicolumn{2}{|c|}{ Asymmetrical } & \multicolumn{2}{|c|}{ Symmetrical } \\
\hline & $\begin{array}{c}\text { Party A } \\
\text { (challenger) }\end{array}$ & $\begin{array}{c}\text { Party B } \\
\text { (defendant) }\end{array}$ & Party A & Party B \\
\hline Perceived success & $2.03^{\mathrm{a}}(1.02)$ & $2.95^{\mathrm{b}}(1.32)$ & $2.55^{\mathrm{ab}}(1.15)$ & $2.50^{\mathrm{ab}}(1.48)$ \\
\hline Problem solving & $0.80^{\mathrm{a}}(1.62)$ & $-0.37^{\mathrm{b}}(1.69)$ & $-0.02^{\mathrm{a}}(1.45)$ & $0.08^{\mathrm{ab}}(2.16)$ \\
\hline Contending & $-0.14^{\mathrm{a}}(1.56)$ & $-1.54^{\mathrm{b}}(1.83)$ & $-0.57^{\mathrm{ab}}(1.60)$ & $-0.54^{\text {ab }}(2.07)$ \\
\hline Avoiding & $-0.62^{\mathrm{x}}(1.40)$ & $0.59^{y}(1.79)$ & $0.03^{x y}(1.30)$ & $0.16^{x y}(1.48)$ \\
\hline Yielding & $0.18^{\mathrm{a}}(1.21)$ & $-0.35^{\mathrm{a}}(1.32)$ & $0.60^{\mathrm{a}}(1.44)$ & $-0.12^{\mathrm{a}}(1.27)$ \\
\hline
\end{tabular}

Notes: ${ }^{\mathrm{a}, \mathrm{b}}$ Means not sharing the same superscript differ, according to between-subjects $t$ tests, at $p<.05$.

x,y Means not sharing the same superscript differ, according to between-subjects $t$ tests, at $p<.10$.

Standard deviations are in parentheses. 
condition $\times$ role interaction $(F(1,37)=5.50$, $p<.025)$. As can be seen in Table 2, challengers in asymmetrical conflicts perceived themselves to be less successful than their counterparts in the defendant role did; in symmetrical conflicts no such difference in perceived success was observed. Thus, Hypothesis 4 is supported.

\section{Discussion}

Experiment 1 provided support for several of our predictions. Challengers in asymmetrical conflicts engaged in more problem solving, more contending, and (somewhat) less avoiding than their counterparts in the defendant role (Hypotheses 1-3); Also, challengers in asymmetrical conflicts perceived themselves to be less successful than their counterparts in the defendant role (Hypothesis 4).

\section{Experiment 2}

In Experiment 2 we aimed, first of all, to replicate the results of Experiment 1. We make one important amendment, however, in that we replace the self-reported measure of perceived success by observer rating of success. We did so to exclude the possibility that self-serving tendencies on behalf of the conflict parties biased perceived success ratings and, second, to reduce validity threat in terms of commonsource variance. Also, because Experiment 1 revealed no systematic differences across time (see note 3) for conflict management behavior we chose a more efficient way of assessing conflict management behavior. Thus, in contrast to Experiment 1 we relied on a well-validated self-report measure of conflict management (for further detail see the method section below). Once again, it is important to note that possible correlations between self-reports of conflict management on the one hand, and observer reports of conflict outcomes cannot be attributed to common-source bias.

Our second goal with Experiment 2 was to further our understanding of the psychological processes underlying the behavioral results observed in Experiment 1. In the introduction, we argued that the behaviors of challengers and defendants in asymmetrical conflicts may be due to the Status Quo Bias. Notably, we argued that defendants would have resistance to change because they were more likely than challengers to have a loss frame (Hypothesis 5), and to experience more control over the situation (Hypothesis 6). We also expected defendants' tendency to be relatively stubborn and intransient to translate into person perception. Specifically, we predicted that challengers in asymmetrical conflicts would see their counterparts in the role of defendant as less friendly (Hypothesis 7a) and more dominant (Hypothesis 7b) than defendants in asymmetrical conflicts would see their counterparts in the role of challenger.

Our third and final goal was to examine a potential moderator of the effects of conflict structure. Thus far we assumed that conflict parties were motivated by a high concern for their own outcomes, and we left unspecified whether parties were, or were not, concerned about their counterparts' interests and outcomes. Ample research in social and organizational psychology has, however, shown that people differ in their so-called social value orientation, with some being pro-self and concerned about their own outcomes only. Others, in contrast, are pro-social and concerned with own and others' outcomes, as well as with fairness (McClintock, 1977; Van Lange, 1999). This distinction between dispositional pro-self versus pro-social orientations explains a wide variety of behaviors, including cooperative decision making in social dilemmas (e.g. Liebrand, Jansen, Rijken, \& Suhre, 1986), concession making in negotiations (De Dreu \& Boles, 1998; De Dreu \& Van Lange, 1995; Olekalns, Smith, \& Walsh, 1996), and problem solving in conflicts between organizational departments (Nauta, De Dreu, \& Van de Vaart, 2002). These works suggest that challengers and defendants with a pro-social orientation will be more likely to engage in problem solving and yielding, and less likely to engage in contending and avoiding than challengers and defendants with a pro-self orientation.

Few studies have considered heterogeneity of value orientation within conflict dyads-what 
happens when a pro-social is paired to a proself rather than another pro-social. Pro-self individuals tend to behave non-cooperatively, whereas pro-social individuals tend to trust others and approach them in a cooperative way (Pruitt \& Kimmel, 1977; Van Lange, 1999). When their counterpart is pro-self, however, pro-social individuals change their pro-social inclination into non-cooperation to defend themselves against others' non-cooperative stance (e.g. Kelley \& Stahelski, 1970), and also because of the moralistic desire to 'teach the other a lesson' (Steinel \& De Dreu, 2004; Van Lange, 1992). Thus, we expected dyads to engage in more cooperative problem solving when both parties have a pro-social orientation, than when at least one has a proself orientation.

Challengers are, by nature of their position, concerned with their counterparts' goals, interests, and outcomes-they need to understand their counterparts to be able to persuade them or to work together toward a mutually satisfactory agreement. In contrast, defendants need not be concerned with their counterparts' goals, interests, and outcomes-they do not need to understand their counterparts to maintain and secure the status quo. However, we expect this to be true especially for pro-self defendants and less for pro-social defendants whose value orientation drives them toward a cooperative attitude vis-a-vis their counterparts. In other words, we expected that the results observed in Experiment 1 would be especially true when the defendant is pro-self rather than pro-social in orientation. Put differently, we expected the effects predicted in Hypotheses 1-4 to be stronger when parties had a pro-self, rather than pro-social orientation.

\section{Method}

Design Experiment 2 employed a similar roleplaying methodology as in Experiment 1. Participants were provided with background information in which a conflict situation was described and then freely interacted with each other to discuss the issue. A third student observed the interaction and rated the outcomes of both parties.
Like in Experiment 1, the conflict situation yielded a challenger who wanted to change the status quo coupled with either another challenger (symmetrical conflict condition) or a defendant who wanted to maintain the status quo (asymmetrical conflict condition). The design was 2 (Conflict Structure: Symmetrical vs. Asymmetrical) $\times 2$ (Role: Party A vs. Party B) with Conflict Structure manipulated between dyads and Role manipulated within dyads. The dependent variables were the observed conflict behavior and outcomes.

Participants and procedure Ninety-six psychology students (36 males and 60 females; mean age $=21.4)$ at Utrecht University participated in this experiment as part of a workshop on group conflict and negotiation. Initial analyses revealed no differences between male and female participants, nor between dyads composed of same or different gender. Because six participants failed to make consistent choices in the social value orientations measure (see below), they were dropped from the analyses, leaving a total sample size of 90 .

Participants came to the classroom, were asked to complete a measure of social value orientation (see below), and received general instructions about the workshop. Participants were randomly assigned to groups of three students, two conflict parties, and one observer. Participants in the role of conflict party had 10 minutes to read their role instructions (see below). They were to imagine that they were in the described situation and to prepare a conversation with the other participant. They then filled out the pre-conversation questionnaire. In the meantime, participants in the role of observer received rating instructions. Groups were then seated in separate parts of the classroom where conflict parties engaged in a conflict resolution process. After 15 minutes, the observer ended the discussion. Conflict parties then completed the post-conversation questionnaire and observers filled out the conflict rating form. Upon completion of the questionnaire, participants were debriefed and received additional information about group conflict and negotiation. 
Assessment of social value orientation Social value orientation was assessed using the Kuhlman and Marshello (1975) decomposed game measure-a measurement technique which has been demonstrated to have good internal consistency (e.g. Liebrand \& Van Run, 1985), test-retest reliability (Kuhlman, Camac, \& Cunha, 1986) and construct validity (De Dreu \& Boles, 1998). Parks (1994) and Kuhlman and Marshello (1975) reported moderate negative correlations between this measure and a measure of generalized distrust, i.e. the F scale (Robinson \& Shaver, 1973). The measure was introduced by the following instructions:

Below you see nine decisions in which you have to make a choice. Your choice influences the amount of points you and some other person will get. Think of the points as something that is valuable to you, to which you attach great importance. The other person also attaches great importance to the points. Think of the other person as someone you do not know, and you will never meet.

Participants were subsequently asked to make decisions in nine so-called decomposed games.

In each decomposed game, participants could choose from different distributions of outcomes to themselves and a another (hypothetical) person. Outcomes were presented in terms of points which were said to have value to both themselves as well as to the other person. Participants were given a choice among three alternatives, each corresponding to one of the social value orientations under study. In total, there were nine decomposed games, derived from prior work of Kuhlman and Marshello (1975). An example of the decomposed games used in the current study involves a choice among Option 1 (50 to Self; 20 to Other), Option 2 (45 to Self; 45 to Other), and Option 3 (40 to Self; 0 to Other). Option 1 represents the individualistic choice because one's own outcomes are larger (50) than are those in Option 2 (45) or Option 3 (40). Option 3 represents the competitive option, because it provides a greater advantage over the other's outcomes $(40-0=40)$ than either Option $1(50-20=30)$ or Option 2 $(45-45=0)$. Finally, Option 2 corresponds to a pro-social choice because it provides a larger joint outcome $(45+45=90)$ than either Option 1 $(50+20=70)$ or Option $2(40+0=40)$.

To be classified into one of the three social value orientations, participants had to choose consistently at least six of the nine trials. Using this criteria, 55 (27 in the to be assigned role of Party A) were classified as pro-social, 9 as competitive, and 26 as individualists. Consistent with past work in this area, competitive and individualistic participants were put together in the pro-self category (18 in the to be assigned role of Party A). Six participants failed the criterion of making six consistent choices (were unclassifiable) and were dropped from the analyses, leaving a total sample size of 90 participants.

Conflict task The task was the same as the one used in Experiment 1.

\section{Dependent variables}

Conflict management In the post-discussion questionnaire, we included the Dutch Test for Conflict Handling (Van de Vliert, 1997). This scale measures inaction, contentious behavior ('contending'), concession making ('yielding'), and problem solving. De Dreu et al. (2001) showed moderate to strong correlations between post-negotiation self-reports on inaction, contentious behavior, concession making, and problem solving on the one hand, and observer codings for these strategies on the other. Sample items included 'during the negotiation I avoided discussing certain issues' (inaction; Cronbach's $\alpha=.63$ ), 'I fought for good outcomes for myself' (contentious behavior; $\alpha=.72$ ), 'I made concessions to accommodate the other party' (concession making; $\alpha=.81$ ), and 'I tried to find solutions that satisfied my own and the other party's interests' (problem solving; $\alpha=.79$ ) (all items: $1=$ not at all, to $5=$ very much). Ratings were averaged into indices of inaction, contentious behavior, concession making, and problem solving, respectively.

Framing and perceived control Following the measure of conflict management, participants 
were asked to fill out several items intended to measure their framing of the conflict ('achieving my goal would be a gain', and 'not reaching my goal would be a loss'; both 1 = definitely not, to 7 = very much), and the amount of experienced control over their outcomes ('I have more control over the outcome of the conflict than my counterpart', and 'my counterpart can determine the conflict outcomes more than I can'; both 1 = certainly not, to 7 = definitely). In each case ratings on the second question were reverse coded and within constructs aggregated into one index for framing $(r=.67$ for Party A, and $r=.61$ for Party $\mathrm{B}$; higher scores indicating more loss frame) and perceived control $(r=.75$ for Party A, and $r=.68$ for Party B; higher scores indicating more perceived control).

Person perception This was measured by asking participants to rate on a 5-point scale their counterparts on a number of adjectives. Four of these related to others' friendliness (cooperativecompetitive; friendly-hostile; trustworthy-not trustworthy; pleasant-unpleasant) and were grouped together into one index of friendliness (Cronbach's $\alpha=.81$ and .82 for Party A's perception of others' friendliness, and Party B's perception of others' friendliness, respectively). Three adjectives related to others' dominance (dominant-submissive; bossy-obedient; directive-easy-going), and were grouped together into one index of dominance (Cronbach's $\alpha: .81$ and .82 for Party A's perception of others' dominance, and Party B's perception of others' dominance, respectively).
Conflict outcomes In contrast to Experiment 1, in which outcome measures were based on self-report, we used observer ratings to assess conflict outcomes. Each discussion was rated by an independent observer $(N=45)$. Observers rated the conflict outcome for each party on three 5-point scales (Party A(B) got what s/he wanted; Party A(B) achieved his/her goals; Party A(B) was successful in satisfying his/her wishes; always $1=$ not at all, to $5=$ to a great extent) . Ratings were within party aggregated into one index for outcomes to Party A and outcomes to Party B.

\section{Results \\ Conflict management (Hypothesis 1-3)}

Problem solving Party A's problem solving and Party B's problem solving were submitted to a 2 (Symmetrical vs. Asymmetrical Conflict Structure) $\times 2$ (Party A is Pro-social vs. Pro-self $) \times 2$ (Party B is Pro-social vs. Pro-self) $\times 2$ (Role: Party A vs. Party B) mixed-model ANOVA with the last factor within-dyads. Results showed, first of all, an interaction between conflict structure and role $(F(1,82)=4.94, p<.03)$. As can be seen in Table 3, Party A's challengers in asymmetrical conflicts engaged in more problem solving than their counterparts in the defendant role; in symmetrical conflicts no difference between both challengers A and B were significant. This replicates the results obtained in Experiment 1 and implies new support for Hypothesis 1 .

Second, results showed a trend toward a main effect for Party B's value orientation, so that dyads engaged in more problem solving when Party

Table 3. Means for conflict outcomes and problem solving as a function of conflict structure and party role: Experiment 2

\begin{tabular}{lccccc}
\hline & \multicolumn{3}{c}{ Conflict structure } \\
\cline { 2 - 5 } & \multicolumn{2}{c}{ Asymmetrical } & \multicolumn{2}{c}{ Symmetrical } \\
\cline { 2 - 5 } & $\begin{array}{c}\text { Party A } \\
\text { (challenger })\end{array}$ & $\begin{array}{c}\text { Party B } \\
\text { (defendant) }\end{array}$ & Party A & Party B \\
\hline Conflict outcome & $56.21^{\mathrm{a}}(9.08)$ & $70.30^{\mathrm{b}}(10.32)$ & $64.82^{\mathrm{ab}}(9.15)$ & $67.70^{\mathrm{ab}}(11.48)$ \\
Problem solving & $5.08^{\mathrm{a}}(1.62)$ & $4.41^{\mathrm{b}}(1.69)$ & $4.92^{\mathrm{ab}}(1.45)$ & $4.67^{\mathrm{ab}}(2.16)$ \\
\hline
\end{tabular}

Notes: ${ }^{\mathrm{a}, \mathrm{b}}$ Means not sharing the same superscript differ, according to between-subjects $t$ tests, at $p<.05$.

Standard deviations are in parentheses. 
B was pro-social rather than pro-self $(M=4.97$ vs. $M=4.53, F(1,82)=2.94, p<.10)$. No other effects involving social value orientation were significant. Thus, social value orientation does not moderate the influence of conflict structure on conflict outcomes.

Contending Party A's contending and Party B's contending were submitted to a 2 (Symmetrical vs. Asymmetrical Conflict Structure) $\times 2$ (Party A is Pro-social vs. Pro-self) $\times 2$ (Party $\mathrm{B}$ is Prosocial vs. Pro-self) $\times 2$ (Role: Party A vs. Party B) mixed-model ANOVA with the last factor within-dyads. Results showed, first of all, a main effect for conflict structure $(F(1,82)=4.97$, $p<.03)$. Asymmetrical conflicts produced more contending than symmetrical conflicts $(M=4.57$ vs. $M=4.33$ ). However, because there was no qualifying interaction with role $(F(1,82)<1)$, we do not replicate the results in Experiment 1.

Second, results showed a main effect for Party B's value orientation, so that dyads engaged in less contending when Party B was pro-social rather than pro-self $(M=4.32$ vs. $M=4.57$, $F(1,82)=7.40, p<.01)$. No other effects involving social value orientation were significant. Thus, social value orientation does not moderate the influence of conflict structure on contending.

Avoiding Party A's avoiding and Party B's avoiding were submitted to a 2 (Symmetrical vs. Asymmetrical Conflict Structure) $\times 2$ (Party A is Pro-social vs. Pro-self) $\times 2$ (Party B is Pro-social vs. Pro-self) $\times 2$ (Role: Party A vs. Party B) mixedmodel ANOVA with the last factor within-dyads. Results only showed a main effect for Party B's value orientation, so that dyads engaged in more avoiding when Party B was pro-social rather than pro-self $(M=3.57$ vs. $M=3.30, F(1,82)=6.94$, $p<.01)$. No other effects involving social value orientation were significant. Thus, social value orientation does not moderate the influence of conflict structure on avoiding.

Yielding Party A's yielding and Party B's yielding were submitted to a 2 (Symmetrical vs. Asymmetrical Conflict Structure) $\times 2$ (Party A is Pro-social vs. Pro-self) $\times 2$ (Party B is Prosocial vs. Pro-self) $\times 2$ (Role: Party A vs. Party B) mixed-model ANOVA with the last factor withindyads. Results showed a main effect for Party B's value orientation, so that dyads engaged in more yielding when Party B was pro-social rather than pro-self $(M=4.20$ vs. $M=3.89$; $F(1,82)=6.86, p<.01)$. Similarly, there was a main effect for Party A's value orientation, so that dyads engaged in more yielding when Party A was pro-social rather than pro-self $(M=4.10$ vs. $M=3.84, F(1,82)=5.67, p<.02)$. No other effects involving social value orientation were significant. Thus, social value orientation does not moderate the influence of conflict structure on yielding.

Conflict outcomes (Hypothesis 4) Party A's outcomes and Party B's outcomes were submitted to a 2 (Symmetrical vs. Asymmetrical Conflict Structure) $\times 2$ (Party A is Pro-social vs. Proself) $\times 2$ (Party B is Pro-social vs. Pro-self $) \times 2$ (Role: Party A vs. Party B) mixed-model ANOVA with the last factor within-dyads. Results showed, first of all, a main effect for conflict structure $(F(1,82)=8.94, p<.005)$, and a qualifying interaction between conflict structure and role $(F(1,82)=4.91, p<.03)$. As can be seen in Table 3 , Party A challengers in asymmetrical conflicts achieved lower outcomes than their counterparts in Party B in the defendant role. This replicates the results obtained in Experiment 1 and implies new support for Hypothesis 4.

Second, results showed a main effect for Party B's value orientation, so that dyads achieved higher outcomes together when Party B was pro-social rather than pro-self $(M=66.00$ vs. $M=59.48$, $F(1,82)=8.52, p<.005)$. No other effects involving social value orientation were significant. Thus, social value orientation does not moderate the influence of conflict structure on conflict outcomes.

\section{Loss framing and perceived control (Hypotheses}

5-6) Loss framing by Party A and loss framing by Party B were submitted to a 2 (Symmetrical vs. Asymmetrical Conflict Structure) $\times 2$ (Party A is Pro-social vs. Pro-self) $\times 2$ (Party B is Pro-social vs. Pro-self) $\times 2$ (Role: Party A vs. Party B) mixedmodel ANOVA with the last factor within-dyads. The only significant effect was an interaction 
between conflict structure and role $(F(1,82)=$ $11.13, p<.001)$. As can be seen in Table 4, Party A (challenger) experienced less of a loss-frame than Party B (defendant) in the asymmetrical conflict condition, whereas Parties A and B did not differ in the symmetrical conflict condition. This supports Hypothesis 5 and our reasoning that defendants are relatively resistant to change because they are in a loss-frame more than their challenger is.

Perceived control by Party A and perceived control by Party B were submitted to a 2 (Symmetrical vs. Asymmetrical Conflict Structure) $\times 2$ (Party A is Pro-social vs. Pro-self) $\times 2$ (Party B is Prosocial vs. Pro-self) $\times 2$ (Role: Party A vs. Party B) mixed-model ANOVA with the last factor within-dyads. Results revealed a significant main effect for conflict structure $(F(1,82)=19.71$, $p<.001)$, and a qualifying interaction between conflict structure and role $(F(1,82)=8.40$, $p<.005)$. As can be seen in Table 4, Party A (challenger) experienced less control than Party B (defendant) in the asymmetrical conflict condition, whereas Party A and Party B did not differ in the symmetrical conflict condition. This supports Hypothesis 6 and our reasoning that defendants are relatively resistant to change because they are in a more powerful position than their challenger is.

Person perception (Hypotheses 7a-7b) Other's friendliness perceived by Party A and other's friendliness perceived by Party B were submitted to a 2 (Symmetrical vs. Asymmetrical Conflict
Structure) $\times 2$ (Party A is Pro-social vs. Proself $) \times 2$ (Party B is Pro-social vs. Pro-self $) \times 2$ (Role: Party A vs. Party B) mixed-model ANOVA with the last factor within-dyads. This revealed a main effect for Party A's social value orientation, showing that Party A perceived party B as friendlier when Party A had a pro-social rather than a pro-self orientation ( $M=4.77$ vs. $M=4.06$; $F(1,82)=5.89, p<.025)$. A similar, albeit less strong, main effect for Party B's social value orientation showed that Party B perceived party A as friendlier when Party B had a pro-social rather than a pro-self orientation $(M=4.42$ vs. $M=3.93 ; F(1,82)=3.07, p<.084)$ (marginal). Finally, results revealed a trend toward an interaction among conflict structure and role $(F(1,82)=3.24, p<.075)$ (marginal). Cell means in Table 4 show that party A (challenger) perceives party $\mathrm{B}$ (defendant) as less friendly than party $\mathrm{B}$ perceives party $\mathrm{A}$ in asymmetrical conflicts, whereas there appears to be no divergence in perceptions of friendliness in symmetrical conflicts. This matches our notion that defendants may be more stubborn, evasive, and resistant to change than challengers, and provides support for Hypothesis 7a.

Other's dominance perceived by Party A and other's dominance perceived by Party B were submitted to a 2 (Symmetrical vs. Asymmetrical Conflict Structure) $\times 2$ (Party A is Pro-social vs. Pro-self) $\times 2$ (Party B is pro-social vs. proself) $\times 2$ (Role: Party A vs. Party B) mixed-model ANOVA with the last factor within-dyads. This only revealed an interaction among conflict

Table 4. Means for conflict-related perceptions as a function of conflict structure and party role: Experiment 2

\begin{tabular}{|c|c|c|c|c|}
\hline & \multicolumn{4}{|c|}{ Conflict structure } \\
\hline & \multicolumn{2}{|c|}{ Asymmetrical } & \multicolumn{2}{|c|}{ Symmetrical } \\
\hline & $\begin{array}{c}\text { Party A } \\
\text { (challenger) }\end{array}$ & $\begin{array}{c}\text { Party B } \\
\text { (defendant) }\end{array}$ & Party A & Party B \\
\hline Loss-frame & $2.97^{\mathrm{b}}$ & $3.30^{\mathrm{a}}$ & $3.20^{a}$ & $3.04^{\mathrm{ab}}$ \\
\hline Perceived control & $3.78^{c}$ & $5.13^{\mathrm{b}}$ & $4.19^{\mathrm{a}}$ & $4.36^{\mathrm{a}}$ \\
\hline Others' friendliness & $2.39^{\mathrm{b}}$ & $2.99^{\mathrm{a}}$ & $2.71^{\mathrm{a}}$ & $2.61^{\mathrm{ab}}$ \\
\hline Others' dominance & $4.17^{c}$ & $3.47^{\mathrm{ab}}$ & $3.68^{\mathrm{a}}$ & $4.06^{\mathrm{bc}}$ \\
\hline
\end{tabular}

Note: ${ }^{\mathrm{a}, \mathrm{b}, \mathrm{c}}$ Means not sharing the same superscript differ, according to between-subjects $t$ tests, at $p<.05$. 
structure and role $(F(1,82)=7.09, p<.01)$. As can be seen in Table 4, Party B is perceived as more dominant in asymmetrical rather than symmetrical conflicts, and Party $\mathrm{A}$ is perceived as less dominant in asymmetrical rather than symmetrical conflicts; this supports Hypothesis $7 \mathrm{~b}$.

\section{Discussion}

Results replicated and extended those of Experiment 1. Again, and consistent with Hypothesis 4, we found that challengers achieved lower outcomes when paired to a defendant (asymmetrical conflict) than to another challenger. Consistent with Hypothesis 1 , we found once again that challengers in asymmetrical conflicts engaged in more problem solving than their counterparts in the defendant role, than with another challenger. Importantly, we did not replicate the results regarding contending and avoiding obtained in Experiment 1. Although we cannot exclude that this failure to replicate effects is partly due to the fact that we used self-report instead of observer ratings of behavior, this may suggest that conflict outcomes are primarily the result of asymmetries in problem solving. We return to this in the general discussion.

In addition to Experiment 1, we included perceptual measures in Experiment 2. We found that in asymmetrical conflicts defendants are in a loss-frame more than their challengers. Also, defendants perceive more control over the situation. Finally, defendants are perceived as less friendly and more dominant than their challengers. These three findings together strongly support the notion that those defending the status quo are better positioned than those challenging the status quo, and corroborates speculations in other research reports (e.g. Keltner \& Robinson, 1997; Robinson \& Keltner, 1996; Garcia et al., 2001; Kluwer, 1998).

\section{Social value orientations}

In Experiment 2 we included both parties' pro-self versus pro-social value orientation as a potential moderator of the conflict structure effects. However, no interaction between social value orientation, conflict structure, and participant role was found-the effects of conflict structure on perceptions, motivation, and conflict behaviors hold for both pro-self and pro-social individuals. At the same time, we did find a number of effects for parties' social value orientation that merit discussion.

Results for conflict management showed that Party B engaged in more problem solving and less contending when $\mathrm{s} /$ he was pro-social rather than pro-self, and that Party B and Party A engaged in more yielding when they were prosocial rather than pro-self. Also, dyads achieved higher outcomes when Party B was pro-social rather than pro-self. Finally, Party A and B saw each other as friendlier when they were pro-social rather than pro-self. Because no interactions involving conflict structure were observed, we cannot conclude that the stronger effects for Party B were due to the fact that Party B was the defendant in half of the cases. Furthermore, means for Party A went in the same direction but did not reach significance. For some reason, effects for social value orientation were stronger when participants were in the role of Party B, but not qualitatively different when participants were in the role of Party A. We believe this points to the fact that role descriptions have provided Party B with a slightly 'weaker situation' than Party A, allowing person-based tendencies to come out more in Party B than in Party A.

We reasoned that dispute resolution processes are more constructive when parties have a pro-social rather than pro-self orientation. Furthermore, based on the so-called triangle hypothesis (Kelley \& Stahelski, 1970; Steinel \& De Dreu, 2004; Van Lange, 1992), one would expect constructive processes only when both parties are pro-social. This is because pro-socials tend to adapt to, and adopt, the less constructive behavior by their pro-self counterparts. The lack of interactions between Party A and Party B's social value orientation on any of the measures in Experiment 2 goes against this triangle hypothesis. This may indicate that the triangle hypothesis is limited to specific situations, such as prisoner's dilemma type of games (Miller \& Holmes, 1975) and does not necessarily generalize to negotiation and dispute resolution (cf. Weingart, Brett, Olekalns, \& Smith, 2007). 
Indeed, close inspection of the relevant literature suggests rather limited evidence for this triangle hypothesis. While initial evidence has been provided using prisoner's dilemma games (Kelley \& Stahelski, 1970), follow-up work using slight variations of this game failed to provide supportive evidence (Miller \& Holmes, 1975). Studies into cooperative behavior in so-called chicken dilemma games and trust games likewise failed to provide asymmetrical adaptation of prosocials to competitive behavior by their counterpart (Liebrand, Wilke, Vogel, \& Wolters, 1986), and there is little evidence for the underlying proposition that pro-social individuals have more heterogeneous beliefs about others' value orientation than those with a pro-self orientation (e.g. Iedema \& Poppe, 1999). Work by Parks and Rumble (2001; also see Parks, Sanna, \& Berel, 2001) found behavioral assimilation by prosocials more than by pro-selves but only after substantial delay. In short, it appears the triangle hypothesis has some validity in rather specific circumstances (i.e. prisoner dilemma games) and that in other social decision making settings symmetrical adaptation is the rule rather than the exception. Clearly, however, more systematic research into this issue is greatly needed.

\section{Conclusions and general discussion}

Although conflict research and theory has developed in the past three decades, few studies dealt with the fact that the mere structure of the conflict can have important implications for parties' cognitions, motivational goals, social perceptions, behavioral interactions, and conflict outcomes. Granted, in some areas, such as negotiations, symmetrical structures have been studied extensively, and in other areas, such as marital interaction and judicial disputes, asymmetrical structures have been covered in quite some detail. Yet as far as we know the current research is the first to directly compare, in an experimental setting, the possible consequences of symmetrical versus asymmetrical conflicts. Below we discuss these findings, along with some suggestions for future research and implications for conflict and negotiation research. We also address the results for social value orientation obtained in Experiment 2 in some more detail, and we end with some general conclusions.

\section{Conflict structures}

Several findings were consistent across the two experiments. In both studies, we found no differences in problem solving, contending, yielding, avoiding, and conflict outcomes between both challengers A and B in the symmetrical conflict conditions. Clearly, specific role instructions, however minor, had no meaningful influence on the course and outcome of the dispute resolution process. Similarly, in the symmetrical conflict condition of Experiment 2 no differences among challengers were found in loss framing, perceived control, and person perception. However, and consistent with our predictions, meaningful differences in conflict behavior, perceptions, and outcomes between challengers and defendants were found in the asymmetrical conflict conditions. As predicted, challengers engaged in more problem solving and contending, and in less avoiding, had less of a loss-frame, perceived lower control, and obtained lower outcomes than their counterparts in the role of defendant. These findings are consistent with our reasoning that in asymmetrical conflicts challengers need to be pro-active and approach their defendant who, because of the Status Quo Bias, is relatively stubborn, evasive, and domineering. In short, asymmetrical conflicts are less likely to run a constructive course, and are more likely to escalate into impasse or win-lose outcomes, compared to symmetrical conflicts.

At the outset we noted that recent work indicates that feeling powerful may instigate approach motivation and concomitant action tendencies (cf. Keltner, Gruenfeld, \& Anderson, 2003). At first blush this seems to go against our reasoning, and findings, that defendants with concomitantly more power are less pro-active in initiating and reciprocating problem-solving and contending tendencies than their challengers and are, in fact, more likely to remain inactive. However, it may very well be that defendants with a greater sense of power than challengers are initially predisposed to act and move but that 
this basic and habitual tendency is overruled by sophisticated strategic analysis of the pros and cons of (not) acting. That parties to a conflict can and do overcome their initial and habitual tendencies has been shown in work on the social functions of emotions in conflict and negotiation, which revealed that contagion-like processes emerge but do not affect behavior; behavioral responses to other's emotions were grounded in a strategic analysis of the information contained in the counterpart's emotion (Van Kleef, De Dreu, \& Manstead, 2004a, 2004b). This work also indicates a way to test this possibility, namely by varying the extent to which defendants and challengers are able and motivated to process informationif they can, strategic considerations (not) to act will overrule their habitual tendencies; but if they cannot, habitual tendencies take precedence over strategic inclinations and defendants may become even more pro-active than their challengers.

Although our predictions and analyses were focused on differences in psychological processes and behavioral tendencies between challenger and defendant in asymmetrical conflicts, our design allows us to examine whether conflict structures influence dispute resolution processes because it impacts challengers or defendants, or both. In neither Experiment 1 nor Experiment 2 did find we overall main effects for conflict structure. Inspection of cell means in Table 2 (Experiment 1) and Table 3 (Experiment 2) shows that with regard to conflict outcomes and conflict management challengers in symmetrical conflicts take positions that are intermediate and not-significantly different from those taken by challengers and defendants in asymmetrical conflicts. Similar patterns emerged in Table 4 (Experiment 2) where with regard to framing, perceived control, and person perceptions, challengers in symmetrical conflicts took positions that were intermediate and not-significantly different from those taken by challengers and defendants in asymmetrical conflicts. These findings together allow the cautious conclusion that conflict structure has no meaningful impact on the overall group-level processes and outcomes but does exert meaningful influences on the withingroup, between party processes and outcomes. Furthermore, we have no evidence that it is either the challenger or the defendant who is primarily responsible for the different processes and outcomes observed in asymmetrical compared to symmetrical conflicts-both challenger and defendant seem to have an impact and jointly determine the course of action and ultimate outcome of the dispute resolution process.

In Experiment 1, where we worked with observed instances of conflict management, we found circumstantial evidence for reciprocal cooperation in symmetrical conflicts, and lack of reciprocal sequences in asymmetrical conflicts. This was based on correlations and thus represents a rather crude assessment of behavioral interaction sequences. Future research into symmetrical and asymmetrical conflicts would benefit tremendously from the type of sequential analyses employed by Weingart and Olekalns and their colleagues (e.g. Olekalns, Brett, \& Weingart, 2003; Weingart, Prietula, Hyder, \& Genovese, 1999). The rather broad coding intervals used in Experiment 1 and the use of retrospective self-report measures in Experiment 2 do not allow the Markov-chain type of analysis that these scholars offer. The current findings and conclusions may, however, serve as the basis for specific predictions to be tested using such more fine-grained coding of behavior at the level of speaker turns.

Current findings suggest that it may not only be the objective structure of the conflict, but also the way it is perceived, that affects how parties approach and respond to each other. For example, it could be argued that sellers and buyers in trade negotiations are actually in an asymmetrical conflict, with the seller defending the status quo-the selling price asked-and the buyer challenging it (cf. Kahneman et al., 1990; see also Donohue \& Taylor, 2007). This asymmetrical conflict structure accounts for the differences in gain-loss framing, perceived control, and differential outcomes achieved by seller and buyers. Related, it may well be that the objective structure of the conflict has less impact than the subjective experience of conflict structures, with objectively symmetrical 
structures being perceived as asymmetrical by one or both parties. Such subjective perceptions may turn out to be more critical in driving conflict cognition and behavior. Obviously, future research is needed to test these ideas more systematically.

Thus far we have implicitly assumed that conflicts are either symmetrical or asymmetrical. However, in many cases, such as negotiations, multiple issues are dealt with in a more or less simultaneous fashion and it is quite likely that on some issues symmetry exists whereas on other issues asymmetry exists. For example, during contract negotiations, management's top priority is to increase labor's upfront costs for prescription medications, whereas labor wants it to stay as is; labor wants to win the ability to adopt flexible start and stop times, but management has no interest in discussing this. Examining such mixed situations is of great interest and importance, and the current research may provide a basis for such more complex analyses both of strategic choices participants make and of the quality of the agreements they ultimately reach.

Before moving to some practical implications of our results, we should acknowledge that the use of relatively short-lived role simulations with individuals not knowing each other and not anticipating future interaction provides high internal validity, but not necessarily high external validity. In many conflicts, parties do share a history and a future, conflict issues may have important repercussions, and conflict outcomes may have vital consequences for parties' wellbeing and economic prosperity. While these aspects were not part of the role simulations used in the current research, the pattern of results we obtained closely follows those obtained in real-life disputes among married couples (e.g. Kluwer et al., 1997) as well as in judicial disputes between district attornies and public defenders (Garcia et al., 2001). Whereas this other work may be higher in external validity, and at the least shows challenger-defendant patterns in specific applied contexts, the current work contributes to these and other literatures by establishing causal direction as well as by showing that specific context does not necessarily moderate the more basic dispute resolution tendencies that emerge as a function of conflict structure.

\section{Implications for third party intervention}

Our findings have implications for third party interventions. Third parties should be aware of the structure of the conflict when they engage in mediation between two conflict parties. Our results suggest that asymmetrical conflicts are more difficult to mediate than symmetrical conflicts, because of their higher chance of escalation and stalemate due to less reciprocation of problem solving. Moreover, the results show that challengers receive lower conflict outcomes than defendants, which can be a risk for long-term (working) relations because challengers may experience injustice. Work by Jehn, Rupert, and Nauta (2006) has indeed shown that asymmetry of conflicts is negatively associated with satisfaction with mediation. Third parties should therefore acknowledge and address asymmetries in conflict. However, this is not an easy task because for a mediation to succeed, it is important that both parties perceive the mediator as impartial and unbiased. By giving differential attention to one of the parties-for example allowing the challenger more speaking time than the defendant-a third party runs the risk of being perceived as partial and biased. Tactics that may be useful for mediators are, first, to ensure equal speaking time for both parties. Another tactic may be to let the parties redefine their conflict issue in more symmetrical terms. For example, when an employee and his or her supervisor argue about working hours that an employee wants to change whereas the supervisor does not, a third party may ask about the underlying interests and help both parties redefine the conflict issue in terms of these interests-e.g. supervisor lacking capacity, employee wanting more time to spend with his or her family. Underlying interests are by definition goals that parties strive for, and therefore reflect change for both parties rather than a status quo of one of the parties.

\section{Conclusions}

In two experiments we showed that in asymmetrical conflicts challengers engage in more problem 
solving and, to some extent, more contending and less avoiding than their counterparts in the role of defendant. These strategic choices came together with less perceived control, less loss framing, and lower personal outcomes. These findings are consistent with previous conclusions that were based on correlational designs and oftentimes did not allow a clear-cut separation of structure effects and gender (as in marital conflict interactions) or occupational status (as in judicial disputes). However, together with these previous works we can conclude that regardless of the specific issues being addressed, or the specific context within which the conflict takes place, defendants of the status quo are in a much better position during asymmetrical conflicts than their challengers are.

Recall that Coombs (1987) argued that some conflicts arise because opposing individuals want the same thing and must settle for different things, whereas other conflicts arise because individuals want different things and must settle for the same thing. We agreed with Coombs that these two broad classes of conflict structures 'exhaust the domain of conflict' (p. 362), but argued that a further distinction between symmetrical and asymmetrical structures was needed to fully understand how conflict structures affect cognition, motivation, and conflict behavior. The current research supports our argument-it matters whether parties together seek to establish change, or instead have to decide whether to change the situation or not. The latter question appears to be more difficult and is about situations prone to conflict escalation.

\section{Notes}

1. In the present context asymmetrical versus symmetrical structure refers to the extent to which one or both disputants seek change. In some work concerned with group negotiation, the terms symmetrical and asymmetrical have been used to describe situations in which all members opposed each other (symmetrical), or in which some members had aligned preferences that deviated from those of a minority member (e.g. Beersma \& De Dreu, 2002; Polzer, Mannix, \& Neale, 1998; Ten Velden, Beersma, \&
De Dreu, 2007). Also, the terms asymmetrical versus symmetrical have sometimes been used to refer to differences in dependency and power among disputants. Again, this is a different situation that is orthogonal to the current focus.

2. Note that this reasoning is in contrast to research and theory suggesting that feeling powerful induces an approach motivation and tendency to act (e.g. Keltner et al., 2003; Van Kleef, De Dreu, Pietroni, \& Manstead, 2006). We return to this in the general discussion.

3. Readers familiar with the negotiation literature may be interested in whether the tasks we used had so-called integrative potential-the possibility for parties to integrate seemingly opposed aspirations into solutions that provided both with relatively high outcomes. Our tasks did not have this possibility explicitly built in (as in most point-value negotiation tasks; see De Dreu \& Carnevale, 2003), but such creative solutions were neither excluded nor prohibited. However, because our focus was on conflict cognition, interpersonal perceptions, and interaction processes, we did not examine in-depth the type of solutions parties reached, and limited this part of the analysis to felt (Experiment 1) and observed (Experiment 2) success.

4. Exploratory analyses were performed to see whether across time behavioral patterns changed in interaction with conflict structure and role. This was not the case-we only found that over time dyads engaged in more problem solving and less forcing; the prevalence of avoiding and yielding did not change over time. The first author may be contacted for further detail.

5. We decided to analyze each conflict management strategy separately, rather than as one single analysis for two reasons. First, strategies are not necessarily correlated and theoretically it is possible that effects show on one strategy but not others. Second, such an overall analysis could reveal that some conflict management strategies are preferred more than others, but since we had no predictions that would complicate interpretation.

\section{Acknowledgments}

This research was supported by a research grant awarded by the Van der Gaag Foundation to Carsten K. W. De Dreu and Aukje Nauta, and by 
an Aspasia Grant awarded by the Netherlands Organization for Scientific Research (NWO) to Esther Kluwer.

\section{References}

Beersma, B., \& De Dreu, C. K. W. (2002). Integrative and distributive negotiation in small groups: Effects of task structure, decision rule, and social motive. Organizational Behavior and Human Decision Processes, 87, 227-252.

Bottom, W. P., \& Studt, A. (1993). Framing and distributive aspects of integrative negotiation. Organizational Behavior and Human Decision Processes, 56, 459-474.

Brett, J. M., Shapiro, D. L., \& Lytle, A. L. (1998). Breaking the bonds of reciprocity in negotiations. Academy of Management Journal, 41, 410-424.

Carnevale, P. J., \& Pruitt, D. G. (1992). Negotiation and mediation. Annual Review of Psychology, 43, 531-582.

Christensen, A., \& Heavey, C. L. (1990). Gender and social structure in the demand/withdraw pattern of marital conflict. Journal of Personality and Social Psychology, 59, 73-81.

Coombs, C. H. (1987). The structure of conflict. American Psychologist, 42, 355-363.

De Dreu, C. K. W., Beersma, B., Steinel, W., \& Van Kleef, G. A. (2007). The psychology of negotiation: Principles and basic processes. In A. W. Kruglanski \& E. T. Higgins (Eds.), Handbook of basic principles in social psychology (2nd ed., pp. 608-629). New York: Guilford.

De Dreu, C. K. W., \& Boles, T. (1998). Share and share alike or winner takes all? Impact of social value orientation on the choice and recall of decision heuristics in negotiation. Organizational Behavior and Human Decision Processes, 76, 253-267.

De Dreu, C. K. W., \& Carnevale, P. J. (2003). Motivational bases of information processing and strategy in conflict and negotiation. In M. P. Zanna (Ed.), Adances in experimental social psychology (Vol. 35, pp. 235-291).

De Dreu, C. K. W., Carnevale, P. J. D., Emans, B. J. M., \& Van de Vliert, E. (1994). Effects of gain loss frames in negotiation: Loss aversion, mismatching, and frame adoption. Organizational Behavior and Human Decision Processes, 60, 90-107.

De Dreu, C. K. W., Evers, A., Beersma, B., Kluwer, E. S., \& Nauta, A. (2001). A theory-based measure of conflict management strategies in the workplace. Journal of Organizational Behavior, 22, 645-668.

De Dreu, C. K. W., Nauta, A., \& Van de Vliert, E. (1995). Self-serving evaluation of conflict behavior and escalation of the dispute. Journal of Applied Social Psychology, 25, 2049-2066.

De Dreu, C. K. W., \& Van Lange, P. A. M. (1995). Impact of social value orientation on negotiator cognition and behavior. Personality and Social Psychology Bulletin, 21, 1177-1188.

De Dreu, C. K. W., Weingart, L. R., \& Kwon, S. (2000). Influence of social motives on integrative negotiation: A meta-analytical review and test of two theories. Journal of Personality and Social Psychology, 78, 889-905.

Donohue, W. A., \& Taylor, P. J. (2007, July). Role effects in negotiation: The one-down phenomenon. Negotiation Journal, 301-331.

Fiske, S. T. (1993). Controlling other people: The impact of power on stereotyping. American Psychologist, 48, 621-628.

Fobian, C. S., \& Christensen-Szalanski, J. J. J. (1993). Ambiguity and liability negotiations: The effects of the negotiators' role and the sensitivity zone. Organizational Behavior and Human Decision Processes, 54, 277-298.

Fobian, C. S., \& Christensen-Szalanski, J. J. J. (1994). Settling liability disputes: The effects of asymmetric levels of ambiguity on negotiations. Organizational Behavior and Human Decision Processes, 60, 108-138.

Garcia, S. M., Darley, J. M., \& Robinson, R. J. (2001). Morally questionable tactics: Negotiations between district attorneys and public defenders. Personality and Social Psychology Bulletin, 27, 731-743.

Harinck, F., \& De Dreu, C. K. W. (2004). Negotiating interests or values and reaching integrative agreements: The importance of time pressure and temporary impasses. European Journal of Social Psychology, 34, 595-612.

Harinck, F., De Dreu, C. K. W., \& Van Vianen, A. E. M. (2000). The impact of conflict issues on fixed-pie perceptions, problem solving, and integrative outcomes in negotiation. Organizational Behavior and Human Decision Processes, 81, 329-358.

Heavey, C. L., Layne, C., \& Christensen, A. (1993). Gender and conflict structure in marital interaction: A replication and extension. Journal of Consulting and Clinical Psychology, $61,16-27$. 
Iedema, J., \& Poppe, M. (1999). Expectations of others' social value orientations in specific and general populations. Personality and Social Psychology Bulletin, 25, 1443-1450.

Janssen, O., \& Van de Vliert, E. (1996). Concern for other's goals: Key to de-escalation of conflict. International Journal of Conflict Management, 7 , 99-120.

Jehn, K. A., Rupert, J., \& Nauta, A. (2006). The effects of conflict asymmetry on mediation outcomes: Satisfaction, work motivation and absenteeism. International Journal of Conflict Management, 17, 96-109.

Kahneman, D., Knetsch, J. L., \& Thaler, R. H. (1990). Experimental tests of the endowment effect and the Coase-theorem. Journal of Political Economy, 98, 1325-1348.

Kahneman, D., \& Tversky, A. (1984). Choices, values, and frames. American Psychologist, 39 , 341-350.

Kelley, H. H., \& Stahelski, A. J. (1970). The social interaction basis of cooperators' and competitors' beliefs about others.

Journal of Personality and Social Psychology, 16, 66-91.

Keltner, D., Gruenfeld, D. H., \& Anderson, C. (2003). Power, approach, and inhibition. Psychological Review, 110, 265-284.

Keltner, D., \& Robinson, R. J. (1997). Defending the status quo: Power and bias in social conflict. Personality and Social Psychology Bulletin, 23, 1066-1077.

Klinetob, N. A., \& Smith, D. A. (1996). Demandwithdraw communication in marital interaction: Tests of interspousal contingency and gender role hypotheses. Journal of Marriage and the Family, 58, 945-957.

Kluwer, E. S. (1998). Responses to gender inequality in the division of family work: The status quo effect. Social Justice Research, 11, 337-357.

Kluwer, E. S., Heesink, J. A. M., \& Van de Vliert, E. (1996). Marital conflict about the division of household labor and paid work. Journal of Marriage and the Family, 58, 958-969.

Kluwer, E. S., Heesink, J. A. M., \& Van de Vliert, E. (1997). The marital dynamics of conflict over the division of labor. Journal of Marriage and the Family, 59, 635-653.

Kluwer, E. S., Heesink, J. A. M., \& Van de Vliert, E. (2000). The division of labor in close relationships: An asymmetrical conflict issue. Personal Relationships, 7, 263-282.
Kuhlman, D. M., Camac, C., \& Cunha, D. A. (1986). Individual differences in social orientation. In H. Wilke, D. Messick, \& C. Rutte (Eds.), Experimental Social Dilemmas (pp. 151-176). New York: Verlag Peter Lang.

Kuhlman, D. M., \& Marshello, A. (1975). Individual differences in game motivation as moderators of preprogrammed strategic effects in prisoner's dilemma. Journal of Personality and Social Psychology, 32, 922-931.

Liebrand, W. B. G., Jansen, R. W. T. L., Rijken, V. M., \& Suhre, C. J. M. (1986). Might over morality: Social values and the perceptions of other players in experimental games. Journal of Experimental Social Psychology, 22, 203-215.

Liebrand, W. B. G., \& Van Run, G. (1985). The effects of social motives across two cultures on behavior in social dilemmas. Journal of Experimental Social Psychology, 21, 86-102.

Liebrand, W. B. G., Wilke, H. A. M., Vogel, R., \& Wolters, F. J. M. (1986). Value orientation and conformity. Journal of Conflict Resolution, 30, 77-97.

McClintock, C. (1977). Social motivations in settings of outcome interdependence. In D. Druckman (Ed.), Negotiations: Social psychological perspective (pp. 49-77).

Beverly Hills: Sage.

Miller, D. T., \& Holmes, J. G. (1975). The role of situational restrictiveness on self-fulfilling prophecies: A theoretical and empirical extension of Kelley and Stahelski's triangle hypothesis. Journal of Personality and Social Psychology, 31, 661-673.

Nauta, A., De Dreu, C. K. W., \& Van der Vaart, T. (2002). Social value orientation, organizational goal concerns and interdepartmental problemsolving behavior. Journal of Organizational Behavior, 23, 199-213.

Neale, M. A., \& Bazerman, M. H. (1985). The effects of framing and negotiator overconfidence on bargaining behaviors and outcomes. Academy of Management Journal, 28, 34-49.

Olekalns, M., Brett, J. M., \& Weingart, L. R. (2003). Phases, transitions, and interruptions. Modelling processes in multi-party negotiations. International Journal of Conflict Management, 14, 191-211.

Olekalns, M., \& Smith, P. L. (2000). Negotiating optimal outcomes: The role of strategic sequences in competitive negotiations. Human Communication Research, 24, 528-560. 
Olekalns, M., \& Smith, P. L. (2005). Moments in time: Meta-cognition, trust, and outcomes in dyadic negotiations. Personality and Social Psychology Bulletin, 31, 1696-1707.

Olekalns, M., Smith, P. L., \& Walsh, T. (1996). The process of negotiating: Strategies, timing and outcomes. Organizational Behavior and Human Decision Processes, 67, 61-77.

Parks, C. (1994). The predictive ability of social values in resource dilemmas and public goods. Personality and Social Psychology Bulletin, 20, 431-438.

Parks, C. D., \& Rumble, A. C. (2001). Elements of reciprocity and social value orientation. Personality and Social Psychology Bulletin, 27, 1301-1309.

Parks, C. D., Sanna, L. J., \& Berel, S. R. (2001). Actions of similar others as inducements to cooperate in social dilemmas. Personality and Social Psychology Bulletin, 27, 345-354.

Peirce, R. S., Pruitt, D. G., \& Czaja, S. J. (1993). Complainant-respondent differences in procedural choice. International Journal of Conflict Management, 4, 199-222.

Polzer, J. T., Mannix, E. A., \& Neale, M. A. (1998). Interest alignment and coalitions in multiparty negotiation. Academy of Management Journal, 41, 42-54.

Pruitt, D. G. (1998). Social conflict. In D. T. Gilbert, S. T. Fiske, \& G. Lindzey (Eds), The handbook of social psychology (Vol. 2, 4th ed., pp. 470-503). New York: McGraw-Hill.

Pruitt, D. G., \& Kimmel, M. J. (1977). Twenty years of experimental gaming: Critique, synthesis, and suggestions for the future. Annual Review of Psychology, 28, 363-92.

Rahim, A. (1983). A measure of styles of handling interpersonal conflict. Academy of Management Journal, 26, 368-376.

Ritov, I., \& Baron, J. (1992). Status-quo and omission biases. Journal of Risk and Uncertainty, 5, 49-61.

Robinson, J. P., \& Shaver, P. R. (1973). Measures of psychological attitudes. Ann Arbor, MI: Institute for Social Research.

Robinson, R. J., \& Keltner, D. (1996). Much ado about nothing: Revisionists and traditionalists choose an introductory English syllabus. Psychological Science, 7, 18-24.

Samuelson, W., \& Zeckhauser, R. (1988). Status quo bias in decision making. Journal of Risk and Uncertainty, 1, 7-59.
Schweitzer, M. (1994). Disentangling status quo and omission effects: An experimental analysis. Organizational Behavior and Human Decision Processes, 58, 457-476.

Steinel, W., \& De Dreu, C. K. W. (2004). Social motives and strategic misrepresentation in social decision making. Journal of Personality and Social Psychology, 86, 419-434.

Ten Velden, F., Beersma, B., \& De Dreu, C. K. W. (2007). Majority and minority influence in group negotiation: The moderating effects of social motivation and decision rules. Journal of Applied Psychology, 92, 259-268.

Thomas, K. W. (1992). Conflict and negotiation processes in organizations. In M. D. Dunnette \& L. M. Hough (Eds.), Handbook of industrial and organizational psychology (2nd ed., pp. 651-717). Palo Alto, CA: Consulting Psychologists Press.

Van de Vliert, E. (1997). Complex interpersonal conflict behaviour. East Sussex, UK: Psychology Press.

Van de Vliert, E., \& Kabanoff, B. (1990). Toward theory-based measures of conflict management. Academy of Management Journal, 33, 199-209.

Van Kleef, G. A., De Dreu, C. K. W., \& Manstead, A. S. R. (2004a). The interpersonal effects of anger and happiness in negotiations. Journal of Personality and Social Psychology, 86, 57-76.

Van Kleef, G. A., De Dreu, C. K. W., \& Manstead, A. S. R. (2004b). The social effects of emotions in negotiation: A motivated information processing account. Journal of Personality and Social Psychology, 87, 510-528.

Van Kleef, G. A., De Dreu, C. K. W., Pietroni, D., \& Manstead, A. S. R. (2006). Power and emotions in negotiation: Power moderates the interpersonal effects of anger and happiness on concession making. European Journal of Social Psychology, 36, 557-581.

Van Lange, P. A. M. (1992). Confidence in expectations: A test of the triangle hypothesis. European Journal of Personality, 6, 371-379.

Van Lange, P. A. M. (1999). The pursuit of joint outcomes and equality in outcomes: An integrative model of social value orientations. Journal of Personality and Social Psychology, 77, 337-349.

Weingart, L. R., Bazerman, M. H., Thompson, L. L., \& Carroll, J. S. (1990). Tactical behavior and negotiation outcomes. International Journal of Conflict Management, 1, 7-31. 
Weingart, L. R., Brett, J. M., Olekalns, M., \& Smith, P. L. (2007). Conflicting social motives in negotiating groups. Journal of Personality and Social Psychology, 93, 994-1010.

Weingart, L. R., Prietula, M. J., Hyder, E., \& Genovese, C. (1999). Knowledge and the sequential processes of negotiation:

A Markov chain analysis of response-in-kind. Journal of Experimental Social Psychology, 35, 366-393.

Paper received 28 February 2007; revised version accepted 31 October 2007.

\section{Biographical notes}

CARSTEN K. W. DE DREU is professor of psychology at the Univeristy of Amsterdam. He received his PhD from the University of Groningen, the Netherlands, in 1993. He has a longstanding interest in the psychological processes involved in social conflict, group decision making, and creativity and innovation.

ESTHER S. KLUWER is associate professor of social psychology at Utrecht University. She received her PhD from the University of Groningen, the Netherlands, in 1998. Her research concerns the close relationship domain, with a special interest in conflict, justice, forgiveness, and the interface between work and family.

AUKJE NAUTA is professor of psychology at the University of Amsterdam and senior consultant at Randstad HR Solutions. She received her PhD from the University of Groningen, the Netherlands, in 1996. Her research interests include prosocial behavior in organizations, conflict, and employability. 